\title{
On the Translator's Ethics in Tourism Translation
}

\author{
Guoyuhui Huang \\ School of Software and Microelectronics, Peking University, Beijing, China102600 \\ 418954792@qq.com
}

Keywords: Tourism translation; Translator's ethics; Cross-cultural communication

Abstract. This Paper firstly discusses the tourism translation and analyzes two misconceptions in tourism translation. After that, it mainly explores three types of translator's ethics in tourism translation.

\section{Introduction}

There exist a large quantity of problems in tourism translation, which thwart the development of tourism in China. The improvement of the quality of tourism translation is inseparable from the limitations of translators' ethics, which defines translators' code of conduct and the basis for assessment. Translator's ethics is also conducive to the coordination of translation subjectivity. As an important player in tourism translation, the translator serves as a key factor in ensuring the quality of translation, who should live up to the ethical standards as a translator and honor professional commitments. It is necessary and urgent to analyze the translator's ethics in tourism translation, because by keeping to translator's ethics, translators can take account of the interests of original authors, clients and target tourists, thus achieving equal dialogues and exchanges in the cross-cultural communication.

\section{A Brief Introduction about Tourism Translation}

The Definition of Tourism Translation. Professor Chen Gang defines tourism translation as follows: tourism translation belongs to professional translation, which is made for tourism activities, specialty and industry. Generally speaking, tourism translation is a communicative activity of cross-culture, cross-society and cross-psychology. Compared with other types of translation, it is more direct, prominent, typical and comprehensive in terms of cross-culture and cross-psychology.

Two Misconceptions in Tourism Translation. Nowadays there exist two misconceptions in tourism translation which pose a potential threat to the advancement of tourism. One is the abuse of functional translation theory, which causes the absence of translator's professional ethics; the other one is the misconception about cross-cultural perspective, which leads to the loss of cross-cultural ethics.

As tourism translation belongs to practical translation, German functional translation theory headed by Nord has a practical and theoretical significance to tourism translation. According to functional translation theory, the strategy and means of tourism translation are determined by the function of the translation or the purpose of expectations, which emphasize the expected function of the translation on the basis of analysis of the original text. The theory champions that translators should take full consideration of the social and cultural background of foreign tourists as well as their expectations to the translation. As a major breakthrough of the traditional outlook of equivalence, this theory has opened up a novel perspective for the study of the strategy of tourism translation.

However, if a theory is not profoundly understood or mastered, the serious phenomenon of the mistaken application and appropriation of translation theory will unarguably emerge. In terms of this viewpoint, functional translation theory can not escape this mistake without exception. Those who misunderstand this theory try all kinds of means to gain the end, thus leading to the abuse of functional translation theory.

First of all, there exists insufficient understanding of the function of tourism translation in the translation circle with excessive emphasis on the inducing function of tourism. Some people hold the view that tourism translation mainly aims at attracting tourists' attention and inducing the interest in 
tourist destination of some potential visitors while some even maintain that tourism is primarily a commercial activity with the purpose of making profits. Under the guidance of this theory, a large number of translators have accumulated quite a few means of tourism translation according to their own translation practice. But these methods can be concluded as adding, deleting and changing. The strategy of adding, deleting and changing is so general that many a translator utilizes it, makes an excuse for serving the target and randomly adding, deleting and changing the original text. For instance, when they come across poems or couplets, translators choose to delete all; when they are confronted with several specialized nouns, they just casually come up with a word without carefully pondering.

It is extremely important for translators to comprehensively understand the purposes of tourism translation and realize that its function is not only to induce, but also to convey unique cultural information. With regards to the tourism to the outside world, vocative function is not achieved until such unique cultural information is spread to foreign countries, because the true purpose of transnational tourism is to obtain heterogeneous cultural experience. As a result, it is tourism industry that is a commercial activity rather than tourism. We should not mix them. The truth is that tourism is absolutely a cultural activity and a cross-cultural activity. Therefore, if translator puts more importance of inducing function of tourism translation above everything and even overly stress its commercial interests, it will certainly cause the legalization of randomly adding, deleting and changing the original text and eventually make translators lose their professional ethics of translation. If things go on like this, translators will become lazy, that is to say they will deliberately choose to avoid some information by making excuse for cultural and aesthetic differences. It is inevitably detrimental to spread heterogeneous culture.

Admittedly, functional translation theory also has some limitations: it neglects the relationship between the original text and the translation; It ignores the responsibility of spreading culture of translation in the cross-cultural communication. Nord proposes "functionality plus loyalty" to limit translators' excessive freedom and illustrate the interpersonal relationship among translator, original author and readers. Besides, she asks translators to take their legitimate rights into full consideration. Although "functionality plus loyalty" seems to provide professional ethical standards for translators, it, in fact, lessens translators' subjective initiatives and make translator become the tool of fulfilling the purpose of translation for client. It will result in a more serious consequence: translators will not pursue higher goal once they meet clients' needs. Therefore, it is vitally important for translators to shoulder their social missions, regard translation as a creative work and give full play to its cultural and social function. The requirements of client can be thought of as one of the purpose of tourism translation, but translators should never seek for basic values or just care for immediate interests. As is known to all, tourism translation not only relates to the economic interests of a person or a group, but also serves as an important window of opening up to the outside world for China, which is a significant event involving country's image. Hence, in the trend towards commercialization of translation, translators should never be anxious to achieve quick success and get instant benefits, but rationally think about it and adopt translation strategy and means based on cross-cultural communication.

It is widely recognized that tourism translation is an activity of cross-cultural communication. In this process, we should pay attention to not only its function of cultural spread, but also the ethical values of cross-cultural communication.

It is truly inappropriate to just give top priority to the culture of the target language or hold the view that tourism translation should comply with the target's culture and aesthetic standards. For example, most people advocate analogy--similar expressions in the culture of Britain and America--when they deal with the translation of the name of people and location, era, historical events or allusion. Why do we interpret splendid Chinese culture with rich connotation by borrowing western cultural concepts? Although it is really widespread of the phenomenon of domestication in tourism translation, many questions have been aroused: Is it proper to do so? Is it conducive to disseminating and fostering Chinese culture? Is it beneficial to the publicity to the outside world? Of course, we will give the answer of "No" to these questions. It is true that over the past century China remained a passive consumer, whose technology, ideology, lifestyle and even the ethical values are decided by other countries. But nowadays with the rapid development of China's economy, we must establish cultural confidence and contribute 
to the increasingly important role of Chinese culture in world pattern. Namely, we are certainly able to create some new words, offer more interesting historical background and allusions and selectively introduce some idioms, sayings and slang to foreign tourists. In this way, we can achieve more perfect effects of cross-cultural communication because the primary purpose of transnational travel is to learn about other countries' culture. Cross-cultural communication gives rise to differences which in turn add charm to intercultural communication. Therefore, differences in translation should not be hidden but be expressed. The purpose of translation is to reserve differences, not to seek common ground.

In addition, there exist several extreme understanding to foreignization in translation circle, thus leading to the abuse of transliteration, literal translation and even translating word for word in tourism translation. Although transliteration is a useful method in tourism translation, it is not suitable for the translation of the name of all tourist destination, because some of them have the function of both reference and poetic quality. It is advocated to adopt transliteration for the name of subway or street while it is absolutely disapproved of the name of some scenic spots with cultural characteristics and historical allusions.

\section{Three Types of Translator's Ethics in Tourism Translation}

The Ethical Relationship Between Translators and Original Authors. The theory of inter-subjectivity stands for equal dialogues among different subjects on the basis of the principle of respecting each other, instead of advocating the uniqueness of the subject. In the process of tourism translation, the original author represents the creative subject of tourism text while the translator is the subject of interpretation of tourism text. The translator and the original author establish a relationship of mutual recognition and respect. No matter what kind of techniques of language the translator adopts, he/she must translate the materials based on tourism text rather than let words interfere with the sense or even distort the original author's intentions of the tourism text.

Due to different cultural society, living environment and background of era between the translator and the original author, it is inevitable for the translator to interpret the original author's intentions with his/ her own understandings. However, the interpretation of the original author to the tourism text is different from the interpretation of the foreign tourists. In the course of tourism translation, the translator is required to respect the original author, deepen to study and interpret his/ her intentions, and integrate the perspective of the "Other" into his/ her own perspective, thus ensuring the accurate spread of the original author's intentions, objectively and completely conveying all the information of the tourism text to the foreigners and satisfying their desire for knowledge and understanding of Chinese culture.

However, it is very common for translators to conduct the activity of translation without having complete understanding of the true meaning of the materials in tourism translation.

Hence, we can know that if the translator fails to analyze the true meaning of the original author, it is inevitable to convey the false information to the foreign tourists. To avoid such a mistake, the translator should respect the original author and explore his /her true intention in the process of tourism translation. The translator is supposed to accomplish the translation on the basis of the original text. On no account can he/she misunderstand the true intention of the original author.

The Ethical Relationship Between Translators and Clients.Ethics of service first reflects an objective relationship of serving and being served between people and an objective ethical relationship which takes shape in the process of mutual services. The primary quality of service is to be loyal to client while the purpose and principle of service is to finish the tasks from client in accordance with his/ her requirements. There is no doubt that the client will absolutely put forward some requirements according to the purpose, strategy and the target of the service in the tourism translation. Therefore, it will unavoidably exert great impact on the option of the translator. But as we all know, tourism translation is not an activity of a single subject, but an activity of inter-subjectivity involving more than one ethical subject. It is very normal for professional translator in tourism translation is bound to hold his/her own view and understanding on the choice of the occupation of tourism translation and the purpose and strategy of translation. Besides, translators have to take the ethical subjects of clients, original authors 
and foreign tourists into consideration. As Nord points out that it is far less enough to merely meet the needs of the client because translation is of ethical quality. There exist other participants in translation. From the perspective of ethics, if the requirements from client go against the original author or the foreign tourists, the translator has responsibility for pointing it out and even decisively reject it. The service of translator in tourism translation is totally different from other pure commercial services as the translator not only has his/ her own understanding and requirements for translation, but also takes account of the interests and feelings of distinct participants, such as the original author, foreign tourists and so on.

But it is unavoidable for translators to be influenced by the clients and hence revise their original translation according to the clients' requirements. we realize that the clients is bound to raise a multitude of requirements to the purposes and techniques in tourism translation, thus impacting the option of the means of translation. Therefore, it is vitally significant for the translator to put forward his/her own views and take the interests of both the original author and the foreign tourists into full account so as to achieve inter-cultural communication. By no means should the translator just meet the need of the clients while ignoring the interests and feelings of the original author and the foreign tourists.

The Ethical Relationship Between Translators and Foreign Tourists. According to norm-based ethics, norms influences or even determines the production and accept ion of translation. Ethically, the translation must obey the norms of the culture of the target language and live up to the expectations of the target. In the process of tourism translation, these expectations consist of the concrete requirements of the foreign tourists to tourism translation, such as the acceptability and the language style of the translation. However, while the inter-subjectivity of translation recognizes the importance the target's expectations, it puts more emphasis on the necessity of equal dialogues between the translator and the foreign tourists. Although the foreign tourists are the subject of interpretation to the translation, their recognition to the translation is based on the prerequisite of their recognition to the original author and the tourism text, and their reliance on the translator is based on the translator's credibility.

Undeniably, the foreign tourists have manifold expectations: The translator should be fluent to his/her translation which is both accurate and interesting; He/She should be rich in relevant knowledge; At the same time, he/she should take all nation's customs into consideration. Therefore, only when the translator combines the sensitive cross-cultural awareness, proficient application ability of foreign language, extensive knowledge of tourism and strong awareness of service in a perfect way, can the tourism translation meet the psychological expectations of foreign tourists.

From what has suggested, we can clearly know that by utilizing appropriate translation techniques, we can do our utmost to narrow the linguistic and cultural gap between China and the foreign countries, thus living up to the expectations of the foreign tourists and contributing to the inter-cultural communication.

\section{Summary}

This thesis analyzes translator's ethics in tourism translation in order to contribute to the development of tourism industry and the equal exchanges between different cultures in tourism translation--a cross-cultural communication. As is known to all, tourism translation plays an extremely important role in the development of tourism. It is obvious that tourism translation closely relates to a country's history, culture, religion and even all aspects of a region. But nowadays there exist two misconceptions in tourism translation which pose a potential threat to the advancement of tourism. One is the abuse of functional translation theory, which causes the absence of translator's professional ethics; the other one is the misconception about cross-cultural perspective, which leads to the loss of cross-cultural ethics. Therefore, it is vitally important to reclaim two famous models of translator's ethics, which are Pym's ethics model: interculturality and professional concern Chersterman's translation ethics model.

Therefore, translators should conduct the activity of translation on the basis of the professional ethics in the cross-cultural communication, resist utilitarianism, strengthen their self-cultivation and conscientiously assume their social responsibility, thus facilitating the exchanges and integration of Chinese culture and cultures of other countries . 


\section{References}

[1] Pym, Anthony. Pour Une Ethique du Tradcutteur [M]. Arrsa et Ottawa: Artois Preaaes University et Press de I'Universited Ottawa, 1977.

[2] Pym, Anthony. Introduction: The Return to Ethics in Translation Studies[J]. The Translator, 2001(2): 129-138.

[3] Venuti, Lawrence. Translation, empiricism, ethics. Profession[J]. The Modern Language Association of America, 2000.

[4] Venuti, Lawrence. (Ed). The Translation Studies Reader[C]. London \& New York: Routledge, 2000.

[5] Venuti, Lawrence. The Scandals of Translation: Towards an ethics of difference[M]. London \& New York: Routledge, 1998. 